\title{
OS EFEITOS DA RADIAÇÃO LASER ARSENETO DE GÁLIO (AsGa) SOBRE A REGENERAÇÃO DE TENDÕES EM CÃES*
}

\author{
THE EFFECTS OF LASERTHERAPY AsGa ON CANINE TENDON HEALING
}

\author{
Izabelı SCHMITT'; Akeu Gaspar RAISER; Domingulta Lühers GRAÇA’; Cesar Dobler CASTAGNA`; Cristina GEHVER'; Paulo MAIOKKA`
}

\section{RESUMO}

Trinta cāes sem raça definida foram divididos em três grupos e submetidos à tenotomia e tenorrafia do tendăo calcâneo comum direito e esquerdo. No membro esquerdo foi etetuada aplicaçăo laser AsGa $\left(4 \mathrm{j} / \mathrm{cm}^{2}\right)$ para avaliar o processo cicatricial dos mesmos. Posteriormente, as articulaçð̋s do tarso foram imobilizadas durante 11 dias nos animais do grupo I (sacrificados nesta dala) e 21 dias naqueles do grupo II (sacrificados aos 22 dias) e III (sacrificados aos 40) dias de cvolução pósoperatória). Os cāes do grupo Ill foram submetidos a caminhadas diárias de 30 minutos nas duas semanas seguintes para estimular a mobilidade do tendăo. A avaliação clínica dos efeitos dà terapia laser na funcionalidade dos membros foi feita através de exames físicos. Os tendð̃es foram avaliados à necropsia através de análise macroscópica e pelo estudo microscópico realizado $\mathrm{cm}$ todos os segmentos aos 11 (grupo I), vinte e dois (grupo II) e quarenta dias (grupo III) de evolução pós-operatória. O desempenho funcional do membro esquerdo nos animais do grupo III, exposto à radiaçăo laser mostrou-se melhor que no membro direito. Macroscopicamente os tendð̄es irradiados apresentaram melhor vascularizaçăo, menos aderências e cicatrizaçăo com melhor aparência estética que os tendðes testemunhos. Os estudos histológicos revelaram que o laser não interferiu significativamente na produçæo de fibroblastos e na sintese de fibras colágenas.

UNITERMOS: Laser, AsGa; Tendão; Cirurgia; Cães

\section{INTRODUÇĀO}

Os tendðes podem sofrer soluçæo de continuidade quando traumatizados por projéteis de arma de fogo ou por instrumento contante, apresentando ruptura total ou parcial. Além dos ferimentos provocados por traumatismos, a anoxia tecidual é um achado frequiente. $O$ tendão calcâneo comum juntamente com os flexores digitais săo os mais atingidos por estas lesỏes ${ }^{10}$.

A regeneraçăo ocorre por migraçăo e proliferação de fibroblastos do epitendåo9 ou do tecido conjuntivo adjacente. Estas células distribuem-se ao longo do tendão e quando recebem um suprimento sanguíneo favorável começam a sintetizar colágeno. O processo de cicatrização é lento devido à vascularizaçðo local ser deficiente.

Nos tendðes sem bainha sinovial a regeneraçăo ocorre pela invasæo de fibroblastos indiferenciados e brotamentos capilares desde o paratendåo (PEACOCK Van WINKLE", 1976) e tecidos adjacentes lesionados (BLOOMBERG', 1985). Segundo estes autores isto gera aderências que såo mais acentuadas onde houver pontos de sutura.

Estudos experimentais comparativos indicaram o fio de aço inoxidável monofilamento como o mais apropriado para a reparaçăo de tendơes ${ }^{15,16}$. Outro fio de sutura bastante usado é o mononáilon que é um fío forte e com baixo grau de elasucidade facilitando a sua adaptaçăos, 13 .

A técnica de anastomose mais empregada em pequenos animais ế a término-tcrminal porque mantém o diâmetro e 0 comprimento original do tendāo ${ }^{5}$. Os modelos de sutura mais uulizados såo os de Bünell, Bünell-Mayer, Kessler e Kessler modificado ${ }^{6,16}$. A técnica de Bünell tem sido usada com maior freqüência. A tenorrafia segundo a técnica modificada de Kessler é mais eficiente porque năo interfere no suprimento sanguíneo e exige pouca manipulaçăo tecidual reduzindo assim a possibilidade de formaçăo de aderências ${ }^{2.3,2.14}$.

Segundo PEACOCK e Van WINKLE" (1976), após a anastomose o processo de regeneraçăo de tendơcs requer três semanas de completa imobilizaçð̃o do membro, seguido de três semanas de exercício controlado.

A radiaçåo softlaser tem sido utilizada para acelerar processos regencrativos, sendo-lhe imputado aumento no fluxo sangüineo. açăo antiflogística, anticdematosa, analgésica e estimulante do metabolismo celular. ?,12 e da proliferação do fibroblasto responsável pela produçăo de fibra colágena ${ }^{3,12}$.

RUPP $^{3}(1990)$ testou a eficácia da terapia laser AsGa na re-

1 - Médico Velerinário - Universidade Federal de Santa Maria - Rio Grande do Sul

2 - Professor Adjunto - Universidade Federal de de Santa Mana - Rio Grande do Sul

3 - Professor Titular - Universidade Federal de Santa Maria - Rio Grande do Sul

4 - Académico - Curso de Graduação em Medicina Veterinária - Universidade Federal de Santa Maria - Rio Grande do Sul

- Este trabalho é parte da dissertaçao de mestrado apresenuda pelo primeiro autor ao Curso de Pós-graduaçio em Medicina Veteriníria, érea de Cirurgia, da Universidade Federal de Sanla Maria (UFSM). $97119-900$ - Santa Maria, RS. 
paração de lesōes tendinosas em equinos utilizando uma dosimetria de $1,5 \mathrm{j} / \mathrm{cm}^{2}$ durante 10,20 e 50 dias apos a cirurgia corretiva. As análises clínica e histológica não demonstraram variaçðes significativas entre o tendæo tratado e o controle.

Considerando que a dosimetria recomendada para estimular processos regenerativos é de 2 a $4 \mathrm{j} / \mathrm{cm}^{2}$ (CRUÃNES', 1984) é objetivo deste trabalho avaliar o processo cicatricial do tendão calcânco comum de căes submetidos à radiaçăo laser $\mathrm{AsGa}$ numa dosimetria de $4 \mathrm{j} / \mathrm{cm}^{2}$ pontual e $1 \mathrm{j} / \mathrm{cm}^{2} \mathrm{em}$ varredura.

\section{MATERIAL E MÉTODO}

Trinta cłes sem raça definida, clinicamente sadios, machos ou femcas, com idade variando entre 1 e 4 anos, provenientes do Biotério Central da Universidade Federal de Santa Maria foram divididos $\mathrm{cm}$ grupos de 10 animais conforme o tempo de obscrvaçăo pós-operatória. Grupo I, 11 dias; grupo II, 22 dias e grupo III, 40 dias.

Uma semana antes do início do experimento os căes foram desverminados com Disofenol a $3.75 \%(7.5 \mathrm{mg} / \mathrm{kg}, \mathrm{SC})$ e cinco dias apos foi determinado o hemograma e novo exame copro-parasitológico. No pré-operatớrio cada animal sofreu tricotomia ao longo da regiăo compreendida entre os terços proximais da líbia e metatarso. A medicação pré-anestésica constou de Maleato de Acepromazina (1 mg/kg, IV). Passados 20 minutos foi induzida e mantida anestesia geral com Tiopental sódico $3 \%$.

Durante o trans-operatório os animais foram submetidos à adminisuração de soluçăo poliônica (Ringer Lactato) $\mathrm{cm}$ gotejamento venoso de $10 \mathrm{ml} / \mathrm{kg} / \mathrm{h}$.

Após antissepsia do campo operatório pelo esquema álcooliodo-álcool e delimilação com panos de campo esterilizados foi cfetuada incisæo longitudinal de aproximadamente $3 \mathrm{~cm}$ para abordar o tendzo de Aquiles, na regiðo média entre as porçđes teno-muscular e teno-óssea. A diérese, tenotomia e tenorrafia seguiram tếcnica atraumática. Cada tendāo foi submetido à anastomose término-terminal com síntese de Bünell (15 cães) ou de Kessler modificada (15 căes) sendo utilizado fio mononáilon 3-0 agulhado. Os demais planos como paratendăo, tecido subcutâneo e pele foram suturados com mononáilon 4-0 agulhado. Durante a cirurgia as estruturas incididas foram banhadas freqüentemente com soluçăo isotỏnica de cloreto de sódio para evitar o ressecamento. Após a sutura cutânea, as articulaçðes do tarso foram imobilizadas através de transfixação caudo-craneal da túbia e calcâneo com um pino de Steinmann. Este método mais a adaptaçăo de bandagem foram mantidos por 21 dias, periodo em que os căes foram confinados em canis metálicos com restriçăo de exercício. Nas duas semanas seguintes foram submetidos a caminhadas para estimular a mobilidade do tendăo.

A partir do primeiro dia de pós-operatório foi feita aplicaçăo laser diiodo Arseneto de Gálio durante 10 dias da fase de imobilizaçăo $\mathrm{em}$ todos os animais e durante 10 dias da fase de exercício naqueles do grupo III. A dose energética total foi dividida em aplicaçoses de $4 \mathrm{j} / \mathrm{cm}^{2}$ pontual e $1 \mathrm{j} / \mathrm{cm}^{2} \mathrm{em}$ varredura, ao longo da regiāo operada. Estas aplicaçסes foram efetuadas com a extremidade da ampola em contato com a pele dos animais em incidência perpendicular à zona afelada. As aplicaçðes laser foram feitas na área operatóna do membro esquerdo $\mathrm{cm}$ todos os animais. Para as aplicaçoes foi utilizado um aparelho de $45 \mathrm{~W}$ de potência e comprimento de onda de 904 nanômetros***.

Após remoçăo do agente de imobilização, cada animal do grupo III foi avaliado quanto à postura e deambulação em três graus (A, B, C). Foram enquadrados no grau A os animais que apoiaram o membro com firmera no solo, sem sinal de claudicação ou dor. Aqueles que apoiavan com discreta claudicaçăo, mas sem dor, foram enquadrados no grau B. Foram considerados grau $\mathrm{C}$ animais cujo membro operado apresentava claudicação moderada ao apoio, permanecendo em semiflexão quando submetido a exercício passivo.

Os animais do grupo I foram sacrificados e necropsiados aos 11 , os do grupo II aos 22 e os do grupo III aos 40 dias de pósoperatório. Os tendðes irradiados e controle foram examinados macroscopicamente, à necropsia, para avaliar sua espessura, grau de aderència e vascularizaçăo na linha de sutura.

Os cortes histológicos foram corados pela técnica de Hematoxilina \& Eosina para obscrvação da cvolução do processo de regeneração do tendão. Foi utilizada a técnica de Masson para avaliação da maturação das fibras colágenas e a técnica de Von Kossa para demonstrar a presença de cácio no paratendæo.

Com auxilio de uma gratícula NE $35,21 \mathrm{~mm}$ foram realizados estudos morfométricos de contagem de fibroblastos e fibras colágenas por unidade de área, em cinco localizaçðes, dos polos e do centro dos cortes de tecido. Foram avaliados parâmetros como infiltrado inflamatório intersucial c associado a vasos, presença de tecido de granulaçāo, ou crescimento desordenado de células e vasos, presença de cálcio e atividade celular nos envoltórios. A gradaçáo variou de discrew, leve, moderado a marcante.

A contagem morfométrica de fibroblastos e da deposiçăo de fibras colágenas, na área de anastomose, foram submetidas à análise da variância e foram utilizados os testes de F e Tukey para interpretação dos resultados.

\section{RESULTADOS E DISCUSSĀO}

A técnica de tenorrafia término-terminal envolveu apenas um segmento de tendăo, equivalente a $0,5-1,0 \mathrm{~cm}$ de cada coto permitindo aproximaçăo sem tensão. Nos tendðes suturados pela técnica de Kessler modificada foram confirmadas as caraterísticas de não interferir com o suprimento sangüíneo. exigir pouca manipulação e induzir menor resistência, conforme observaram ARON² (1981); KLEINERT et al.' (1981); SERADGE $^{14}$ (1983) e BLOOMBERG' (1985). Este modelo de sutura compromete menos o suprimento vascular que o de Bünell, pois apresenta apenas dois pontos de estrangulamento

- LIV 877: KLD Blossistanas Equipamentos Eletrônicos Leda. Kua Camendador Guimaräes, 25 - 13900-000 Amparo, SP. 
em cada segmento a ser reconstituído, além de proporcionar maior resistência na linha de sutura.

Além de ser um fio forte e com baixo grau de elasticidade, como citaram BLOOMBERG ${ }^{\text {s }}$ (1985) e STRICKLAND ${ }^{15}$ (1989) o fio de mononáilon facilitou a síntese por deslizar facilmente entre as fibras do tendăo permitindo ajuste adequado dos segmentos suturados. Requereu, no entanto, mais cuidado com os nós.

A imobilização da articulação tíbio-tarsiana com pino de Steinmann ofereceu estabilidade para os tendðes cicatrizarem sem tensão nas três primeiras semanas, neutralizando as forças de dispersão que, segundo VAUGHAN ${ }^{16}$ (1987) atuam sobre a linha de sutura. $O$ implante associado à bandagem externa preveniu movimentação excessiva dos animais, permitindo o desenvolvimento de uma fime uniăo entre os segmentos, procedimento fundamental para evitar deiscência da teno-anastomose. O tempo de imobilizaçăo e de exercícios controlados foi o mesmo recomendado para seres humanos por PEACOCK e Van WINKLE" (1976).

Os cães do grupo III adaptaram-se precocemente aos exercícios de flexăo e extensăo forçados o que favoreceu um rápido retorno da funçāo normal do membro. $O$ desempenho funcional do membro esquerdo exposto à radiação laser, nos animais deste grupo, mostrou ser melhor que o membro direito. Este desempenho pode estar relacionado ao aumento no grau de percepção das terminaçð̌es nervosas, induzido pela radiaçæo laser, determinando analgesia“.

Pela avaliaçăo macroscópica à necropsia dos animais sacrificados no $11^{\circ}$ dia de pós-operatório foi observada intensa vascularizaçăo e hemorragia no local de anastomose e tecidos adjacentes, que no tendăo irradiado eram mais discretas e localizadas. No $22^{\circ}$ dia foi verificado espessamento na área de anastomose do tendåo irradiado, menos acentuado, com aderências aos tecidos adjacentes mais discretas e consideradas frágeis se comparadas ao testemunho. Ao $40^{\circ}$ dia após a cirurgia os tendסes submetidos a terapia laser apresentavam área de anastomose homogênea com o restante do tendão enquanto no contra-lateral era mais estreita e irregular (Fig. 1). O testemunho apresentava aderências mais exuberantes aos tecidos adjacentes, denotando menor capacidade deslizante ao movimento da articulação tíbio-tarsiana que o tendăo irradiado onde as aderências eram pouco evidentes e rompiam facilmente ao debridamento. Estes achados sugerem que o laser atua sobre o processo inflamatório modulando a neovascularizaçăo e proliferaçāo fibrosa que, segundo PEACOCK; Van WINKLE" (1976) e BLOOMBERG' (1985) săo as causas das aderências do tendão aos tecidos adjacentes. Pode-se presumir, então, que além do efeito modulador o laser incrementa a nutriçăo e oxigenaçāo tecidual ${ }^{4},{ }^{3} .12 \mathrm{com}$ menor grau de neovascularização induzindo reparação a partir das células do próprio tendåo, possivelmente epitendăo?, com escassas aderências.

Os principais achados histológicos nos tendðes dos animais dos grupos I e II consistiram de migração e proliferaçăo de células, infiltrado polimorfonuclear neutrofílico, tecido de granulação, crescimento desordenado de células e vasos, granuloma de sutura e presença de cálcio no intersúcio e envoltórios. Estes achados apresentaram intensidade de grau variável desde năo observado até marcante, sem definir, no entanto, diferença entre os tendōes irradiados e os testemunhos. Nos animais do grupo III os fibroblastos, vasos sanguíneos e fibras colágenas estavam reorganizados na área cicatricial, perpendicularmente ao cixo longitudinal do tendăo sem variação de um membro para o outro.

A contagem morfométrica de fibroblastos foi efetuada apenas nos segmentos tendíneos dos cães dos grupos II e III, pois a intensa desorganização local dificultou sua visualizaçăo náqueles do grupo I. Năo houve aumento estatisticamente significativo do número de fibroblastos em relação aos testemunhos, nem entre os grupos. Os envoltórios e as porçoes proximal e distal à anastomose mostraram intensa proliferaçăo de fibras colágenas novas (coradas em vermelho pelo tricrômico de Masson - Fig. 2) para o interior da ferida, substituindo as fibras velhas, em todos os animais. A produçāo de fibras colágenas foi mais acentuada nos envoltórios do tendăo irradiado com uma organizaçāo aparentemente mais precoce. A análise estatistica revelou, no entanto, que a colagenização năo foi maior quando comparada aos testemunhos. Entre os grupos lll e II a diferença foi altamente significativa ( $F=0,0021, p>0,01)$. A concentraçăo de fibras no centro da lesăo também năo foi alterada com a irradiação laser, entretanto houve diferença sig. nificativa entre os grupos III e II $(F=0,0021, p>0,01)$ o que era esperado, pois a deposiçåo de fibras colágenas é maior aos 40 que aos 22 dias de pós-operalório.

Os resultados obtidos pela análise histológica demonstram que o laser AsGa não interferiu no processo cicatricial, particularmente na proliferação fibroblástica e deposição de fibras colágenas, mesmo sendo utilizada dosimetria significativamente maior que aquela aplicada por RUPP ${ }^{13}$ (1990) em eqüinos. Assim, este experimento năo oferece subsídios para concordar com as afirmaçð̄es de ANNEROTH et al.' (1988) c $\operatorname{BAXTER}^{3}$ (1988) de que o laser AsGa estimula a proliferaçăo de fibroblastos e em conseqüência a produção de novas fibras colágenas. Possivelmente isto se deva ao fato de os fibroblastos ocorrerem mais nas primeiras $72 \mathrm{~h}$ e os animais deste experimento sacrificados mais precocemente o foram aos 11 dias. Pode-se afirmar, no entanto, que o laser AsGa induz cicatrização de qualidade estética melhor, permitindo regeneraçăo tendinosa com menor grau de aderências.

\section{SUMMARY}

In order to evaluate the influence of lasertherapy on the healing process. Thirty crossbred dogs were divided into three groups (group I, II and III: dogs were sacrificed respective at day $10^{\text {th }}, 21^{*}$ and $40^{\text {th }}$ after starting the experiment) and submitted to tenotomy and tenorraphy of the calcanean common tendon of both limbs. Tarsal joints were fixed for eleven days in those dogs of group I and for twenty-one days on group II and III. All dogs from group III were submitted to daily 30 minutes walks for two weeks in order to stimulate the tendon mobility. AsGa laser was applied daily $\left(4 \mathrm{j} / \mathrm{cm}^{2}\right)$ during ten days on the left limb of all dogs during the first postoperative days and the first ten days of the exercises period for group III. Clinical evaluation of lasertherapy on limb functionality was made by physical examination. Involved tendons were evaluated at 
necropsy and by optic microscopy at eleventh post-operative day (group I), twentieth-first day (group II) and forticth day (group III). Functional performance of the left hind limbs, exposed to the laser beam was better than that of the right limb. Grossly irradiated tendons showed better vascularization, less adherence and better repair than the non-irradiated one. Histological studies showed that laser the rapy did not interfere significantly on fibroblast production and collagem synthesis.

UNITERMS: Laser, AsGa; Tendon; Surgery; Dogs

\section{REFERÊNCIAS BIBLIOGRÁFICAS}

01-ANNEROTH, G.; HALL, G.; RYDEN, H.; ZETTERQVIST, L. The effect of low-energy infra-red laser radiation on wound healing in rats. Brit. J. Oral Maxil. Surg., v. 26, p. 12-7, 1988.

02-ARON, D.N. A "new" tendon stich. J. Amer. Anim. Hosp. Ass., v. 17, p. $587-91,1981$.

03-BAXTER, G.M. Wound healing and delayed wound closure in the lower limb of the horse. Equine Pruct., v. 10, p. 23-31, 1988.

04-BENEDICENTE, A.; GOLA, G.; CIGANO, L. Neuralgia do urigēmio. Avaliação radioimunológica do nível de beta endorfina no líquido céfalo-raquideo antes e depois da irradiação com luz laser 904 nn. Laser Ter. Cir., Ano 0. p. 3-9. 1987.

05-BLOXMBERG, M.S. Muscle and tendons. In: SLATTER, D.H. Textbook of small animal surgery. Philadelphia, W.B. Saunders, 1985. v.2, Cap.166. p. 2331-58.
06-CHICK. L.R.; WALTON, R.L. A history of tendon operations. Sury. Gynecol. Obstet., v. 168, p. 183-8, 1989.

07-CRUÃNES, J.C. La terapia laser hoy. Barcelona, Centro de Documentacion Laser de Meditec. 1984.

08-KLEINERT, H.E.; SCHEPEL. S.; GILL, T. Flexor tendon injuries. Surg. Clin. North Amer., v. 61, p. 267-86, 1981.

09-MANSKE, H.E.; GELBERMAN, R.H.; VANDERBERG, J.S. Intrinsec flexor-tendon repair: a morphological study in vitro. J. Bone Jt. Surg., v. 66-A, p. 385-96, 1984.

10-NIEBERLE, K.; COHRS. P. Anatomla patológica especlal dos animals domésticos. 5.ed. Lisboa, Fundação Calouste Gulbelkian, 1970. v.2.

11-PEACOCK, E.E.; Van WINKLE, W. Surgery und biolugy of wound repair. Philadelphia, W.B. Saunders, 1976.

12-RF, F,; VITERBO, S. Analisi degli effetti biologici dei softlaser. Minerva Hist., v. 34. p. 357-9, 1985.

13-RUPP, S. Experimentelle untersuchungen zur wirkung der (iaAs laser-strahlung $(904 \mathrm{~nm})$ auf Sehnenverletzungen beim pferd. Bern, 1990. Inaugural dissertation (Doktortiels der Veterinacredizinischen) - Veterinaeredizinischen Fakultaet det Universilact Bern.

14-SERADGE, $H$. Elongation of the repair configuration following flexor tendon repair. J. Hand Surg., v. 8, p.182-5, 1983.

15-STRICKLAND, J.W. Flexor tendon surgery. J. Hand Surg., v. 14-B. p. 261-72, 1989.

16-VAUGHAN, L.C. Tendon injury in the dog. Vet. Annual, v. 27. p. $324-8,1987$.

Reccbido para publicażão em 29/06/92 Aprovado para publicação em $10 / 03 / 93$ 

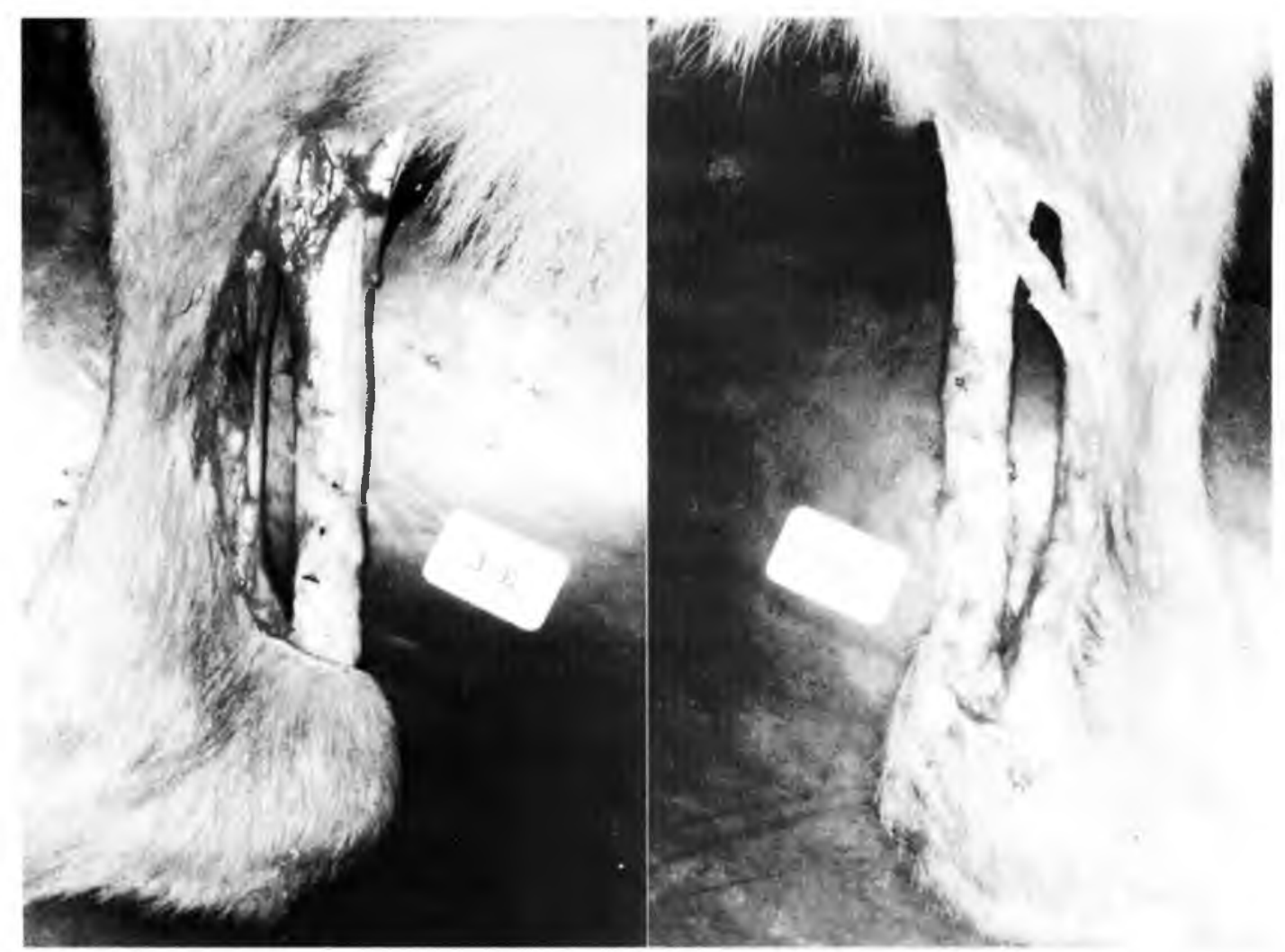

|HGLRA I

Terapia laser AsGa em kendiós. Aspecto macroscópico do processo cicalricial do kendäo submetide à lerapia laser $A$ scia (.3.E) e do lestemunha (1) 3 ) em um cáo lo grupo lll.

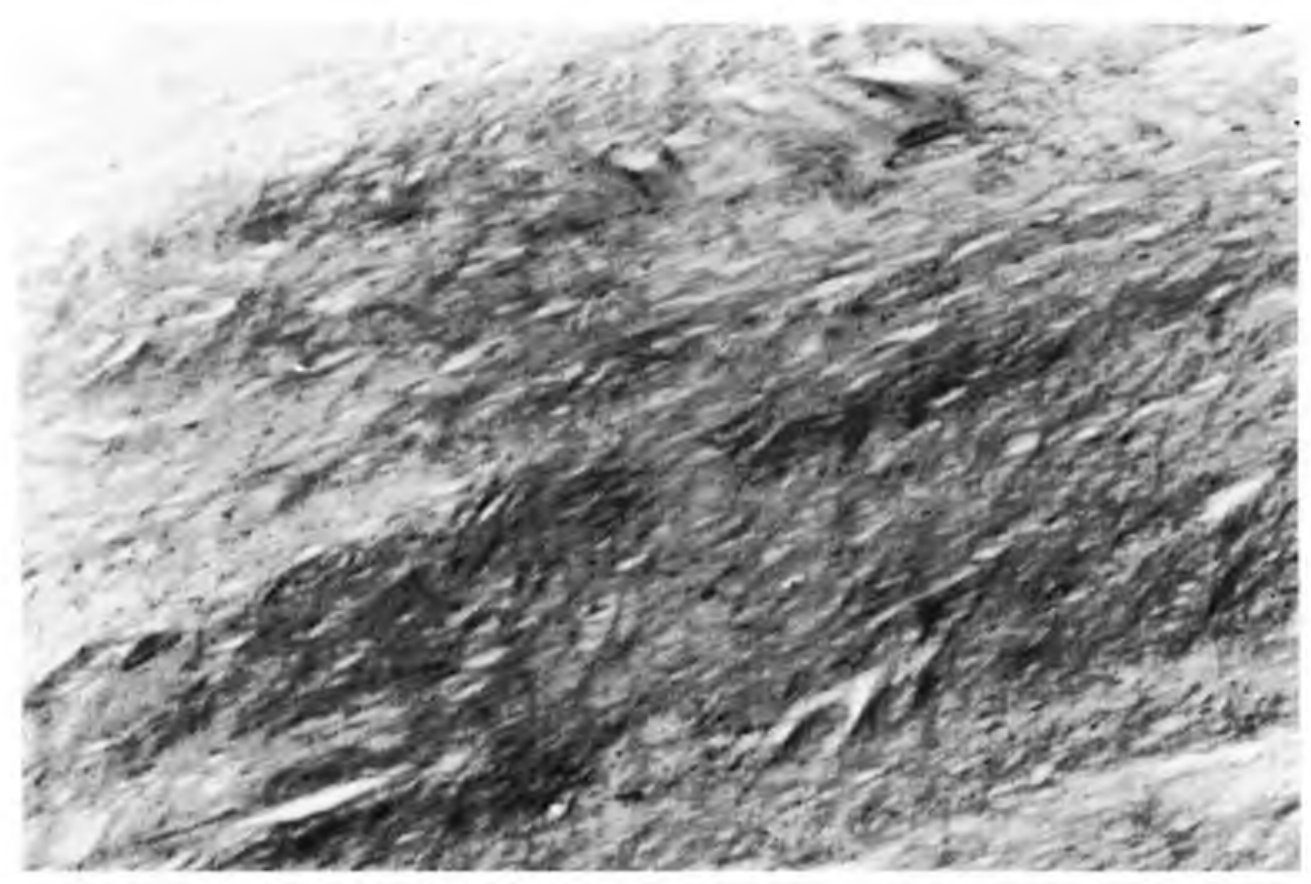

FIGL:RA 2

A terapia laser AsGa na regeneraçāo de tendĩes em cães. lïbras colágcnas novas (coloraçüo avermelhadal) no iendảo irradiado de um cào do grupo llI. Masson $-0.3 \mathrm{X}$. 